

\section{Sumário}

Crimes de Responsabilidade do Presidente da República.............................................. 2 Carlos Ayres Britto

Perda de mandato parlamentar por força de condenaÇão criminal na jurisprudênCia

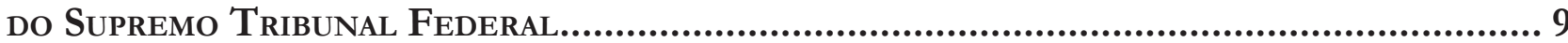
José Levi Mello do Amaral Júnior

Poder NORMATIVO DAS CORTES CONSTITUCIONAIS: O CASO BRASILEIRO.....................................16 Inocêncio Mártires Coelho

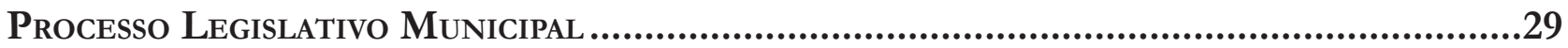
José Levi Mello do Amaral Júnior

Primeiras linhas Sobre a OPÇÃo POlítico-Criminal da Deserção Militar: A NECESSÁRIA contribuição das Políticas Públicas ..............................................................................42

Antonio Henrique Graciano Suxberger e Danilo Gustavo Vieira Martins

IMPLICAÇÕES DO DIREITO AO VOTO AOS IMIGRANTES: AMEAÇA À SOBERANIA NACIONAL OU EFETIVAÇÃO DE UM DIREITO FUNDAMENTAL?

Juliana Cleto

Crimen, Desempleo y Actividad Económica en Chile

Sergio Zuñiga-Jara, Sofía Ruiz Campo e Karla Soria-Barreto

O IMPACTO DE DIFERENTES TIPOS DE REPRESSÃO LEGAL SOBRE AS TAXAS DE HOMICÍDIO ENTRE OS ESTADOS BRASILEIROS 100

Adolfo Sachsida, Mário Jorge Cardoso de Mendonça e Tito Belchior Silva Moreira

Análise dos impactos diretos e indiretos do Programa de P\&D da ANEEL no setor

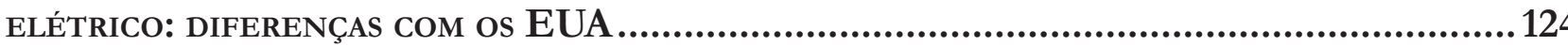
Igor Polezi Munhz, Alessandra Cristina Santos Akkari e Neusa Maria Bastos Fernandes dos Santos

Shango Unchained? State In(Capacity), Urban Bias, and the Power Africa Initiative 146 Tom Brower

LEVANDO O ORÇAMENTO A SÉRIO COMO INSTRUMENTO DE CONTROLE DE POLÍTICAS PÚBLICAS179 Andre Bogossian 
ESTIMATIVA DE DEMANDA PELA FORMALIZAÇÃO DA ECONOMIA INFORMAL NO AGRESTE PERNAMBUCANO: UMA APLICAÇ̃̃o DO MÉTODO DE VALORAÇÃO CONTINGENTE...............................200 Monaliza de Oliveira Ferreira e Kelly Samá Lopes de Vasconcelos

Implicações do Programa Nacional de Alimentação Escolar (PNAE) na renda e orGANIZAÇÃO DE AGRICULTORES FAMILIARES.

Nádia Kunkel Sziwelski, Carla Rosane Paz Arruda Teo, Luciara de Souza Gallina, Fabiula Grahl e Cimara Filippi

Desenvolvimento das famílias E A POBREZA no NORDESTE do BrasiL Nadja Simone Menezes Nery de Oliveira, Solange de Cassia Inforzato de Souza e Aricieri Devidé Junior

EfEITos Colaterais dA MiNERAÇÃo No MEIO AMBIENTE

Márcio Oliveira Portella

ParticipaÇão Popular E ACESSo À INFORMaÇão AMbiental PARa PRESERVAÇÃo do MEIO AMBIENTE ECOLOGICAMENTE EQUILIBRADO 278 Luciano Marcos Paes

Políticas Públicas Para A FormaÇão E AVAliaÇão de Magistrados: A CONTRIbUiÇão da EDUCAÇÃo JUDICIAL ATRAVÉS DAS ESCOLAS DE MAGISTRATURA. 289

Flávio José Moreira Gonçalves

\section{Resenhas}

Simpler: THE FUture of Government, de CAss Sustein 316

Veyzon Campos Muniz 


\title{
Análise dos impactos diretos e indiretos do Programa de P\&D da ANEEL no setor elétrico: diferenças com os EUA*
}

\author{
Analysis of direct and indirect impacts of \\ ANEEL R \& D program in the electricity \\ sector: differences with the U.S.
}

\author{
Igor Polezi Munhz** \\ Alessandra Cristina Santos Akkari*** \\ Neusa Maria Bastos Fernandes dos Santos****
}

* Recebido em 22/04/2015

Aprovado em 28/07/2015

\begin{abstract}
** Doutorando em Engenharia Mecânica, concentração em Engenharia de Controle e Automação Mecânica, na Escola Politécnica da USP, Mestre em Engenharia Elétrica, Bacharel em Engenharia de Produção (Gestão) e Bacharel em Ciência e Tecnologia pela Universidade Federal do ABC (UFABC). Atualmente é professor da Pontifícia Universidade Católica de São Paulo (PUC-SP) e da Universidade Paulista (UNIP) nos cursos de Engenharia. E-mail: igor. munhoz@usp.br.
\end{abstract}

*** Doutora em Farmacologia / Inovação Farmacêutica (2015), Engenheira de Produção (2014) e Bacharel em Ciência e Tecnologia (2011) pela Universidade Federal do ABC. Atua na área de Gestão de P\&D, Elaboração e Análise de Projetos, Inovação e Propriedade Intelectual. E-mail: alessandra.akkari@ufabc. edu.br.

**** Professora Titular da Pontifícia Universidade Católica de São Paulo. Faculty Research Program Fellow - McGill University, Canadá (1996) / Pós-Doutorado, Doutorado em Controladoria e Contabilidade pela USP (1992), Mestrado em Administração pela USP (1984) e Graduação em Administração de Empresas pela USP (1974). Email: admneusa@pucsp.br.

\section{Resumo}

Há grande interesse na avaliação dos impactos da Pesquisa e Desenvolvimento (P\&D), motivado pela necessidade de compreender os seus efeitos e garantir a manutenção dos recursos destinados a esse fim. No setor elétrico, que é um segmento estratégico da economia brasileira, analisar a efetividade desse tipo de programa e mensurar seus impactos torna-se de grande valia a fim de direcionar as políticas públicas. O objetivo deste trabalho consistiu em estudar se existe correlação entre um dos possíveis resultados mensuráveis dos investimentos em $\mathrm{P} \& \mathrm{D}$ regulamentados pela Agência Nacional de Energia Elétrica (ANEEL), o impacto no número de patentes do setor e os impactos indiretos, sob a visão do consumidor, por meio da satisfação dos clientes. Ademais, desenvolveu-se comparação externa com os EUA, país líder na geração de inovação. Para as análises dos dados secundários, aplicou-se o Método dos Mínimos Quadrados, prevendo cenários futuros, e o Método de Pearson, verificando a existência de correlação. Nos EUA, observou-se forte correlação entre o índice de inovação e a satisfação do consumidor; o que não foi possível constatar para o caso brasileiro, possivelmente devido à satisfação do cliente somente ser percebida em longo prazo, enquanto a exploração do processo de inovação no Brasil é recente. Os resultados contribuem para a manutenção de políticas públicas de estímulo aos investimentos em P\&D no Brasil em longo prazo, prevendo a necessidade de mecanismos capazes de mensurar os resultados dos programas, bem como orientar o setor produtivo e facilitar a interação dos diferentes atores do processo de inovação.

Palavras-chave: P\&D. ANEEL. Políticas públicas. Inovação. Satisfação do consumidor.

\section{Abstract}

The aim of this study is to analyze the correlation between the direct (number of patents) and the indirect (customer satisfaction) impacts of R \& 
$\mathrm{D}$ investments in electrical sector. There is a strong correlation between the innovation rate and customer satisfaction in U.S. However, it isn't possible to verify the same situation in Brazil, possibly due to customer satisfaction only be perceived in a long term, while the innovation process exploration is recent in Brazil. These results contribute to $\mathrm{R} \& \mathrm{D}$ public policies maintenance in Brazil. Nonetheless, it is necessary to provide mechanisms to measure the $\mathrm{R} \& \mathrm{D}$ programs results and to facilitate the interaction between different actors in the innovation process.

Keywords: R\&D. Electric sector. Public policies. Innovation. Customer satisfaction.

\section{INTRODUÇÃO}

Há um grande interesse na avaliação da Pesquisa e Desenvolvimento (P\&D), motivado pela necessidade de compreender os efeitos das políticas e dos programas de P\&D, aprendendo com os fatos passados e servindo de fundamento para a continuidade dessas ações ${ }^{1}$. No cenário brasileiro, existem políticas de investimento em $\mathrm{P} \& \mathrm{D}$ em diversos setores da economia, como o elétrico, que é o foco deste trabalho. O setor elétrico como objeto de estudo justifica-se por ser um segmento estratégico, bem como atrela-se à necessidade de enfrentar as drásticas alterações climáticas previstas para as próximas décadas, conferindo importância ao melhor entendimento dos processos de inovação nessa área, a fim de otimizar a capacidade da sociedade moderna em lidar com os novos desafios ${ }^{2}$.

No Brasil, o contexto socioambiental tem estimulado empresas do setor público e privado a se adequarem às novas demandas e a ultrapassarem barreiras ocasionadas pela crescente escassez de recursos no mundo ${ }^{3}$. Nesse sentido, há cerca de quinze anos, ocorreu a promulgação da Lei no 9.991 , de 24 de julho de $2000^{4}$, que determinou que empresas concessionárias, permissionárias e autorizadas do serviço público de energia elétrica realizassem investimentos mínimos em P\&D, segundo o regimento da Agência Nacional de Energia Elétrica (ANEEL).

A ANEEL definiu as condições para execução das pesquisas e para a avaliação e o acompanhamento dos resultados dos projetos de P\&D, conforme descrição no Manual do Programa de Pesquisa e Desenvolvimento Tecnológico do Setor de Energia Elétrica ${ }^{5}$, visando estimular as empresas do segmento em atividades de inovação, a fim de lhes contribuir para enfrentar seus desafios tecnológicos e de mercado. Dessa forma, entende-se que o programa tem como objetivo promover e viabilizar o ciclo completo da cadeia da inovação, incentivando a associação de empresas a desenvolver o conhecimento e transformá-lo em resultados práticos, com o intuito de aprimorar o desempenho organizacional e conferir benefícios para a sociedade ${ }^{6}$.

Tem-se que os investimentos das empresas em P\&D geram efeito positivo na eficiência das mesmas, tornando-as tecnicamente superiores a outras organizações que não efetuam desenvolvem a mesma ação.

1 HASEGAWA, Mirian; FURTADO, André Tosi. Avaliação dos impactos de programas de P\&D. Inovaşão Uniemp, Campinas, v.2, n.3, p. 40-41, jul./ago. 2006.

2 JANSEN, Dorothea; OSTERTAG, Katrin; WALZ, Rainer (Ed.). Sustainability innovations in the electricity sector. New York: PhysicaVerlag, 2012.

3 COSTA, Ana Carolina Vital da; ALMEIDA, José Álvaro Jardim de; GOMES, Carla Regina Pása. Investimentos em P\&D no Setor Elétrico Brasileiro: um perfil dos resultados em eco-inovação. Ariús: Revista de Ciências Humanas e Artes, Campina Grande, v. 16, n. 1/2, p. 172-186, jan./dez. 2010.

4 BRASIL. Lei $n^{\circ}$ 9.991, de 24 de julho de 2000. Dispõe sobre realização de investimentos em pesquisa e desenvolvimento e em eficiência energética por parte das empresas concessionárias, permissionárias e autorizadas do setor de energia elétrica, e dá outras providências. Disponível em:<http://www.planalto.gov.br/ccivil_03/leis/19991.htm>. Acesso em: 18 out. 2014.

5 AGÊNCIA NACIONAL DE ENERGIA ELÉTRICA. Manual dos programas de pesquisa e desenvolvimento tecnológico do setor elétrico brasileiro. Brasília: ANEEL, 2001. Disponível em:<http://www.aneel.gov.br/aplicacoes/leitura_arquivo/default.cfm?idaplicacao=56>. Acesso em: 05 ago. 2015.

6 POMPERMAYER, Fabiano Mezadre; NEGRI, Fernanda de; CAVALCANTE, Luiz Ricardo. Inovação tecnológica no setor elétrico brasileiro: uma avaliação do programa de P\&D regulado pela Aneel. Brasília: IPEA, 2011. 
A elevada eficiência adquirida por meio de atividades de P\&D confere a rentabilidade necessária para que esse processo continue, possibilitando que a empresa sobreviva no mercado e, muitas vezes, obtenha lucros extraordinários advindos da proteção da propriedade intelectual (patentes, por exemplo) gerada no processo de inovação ${ }^{7}$.

Os resultados da P\&D podem ser divididos em diretos e indiretos, e os diretos relacionam-se às metas iniciais do programa, gerando impactos econômicos com base na aplicação comercial do novo produto. Os impactos indiretos, denominados spinoffs, escapam do escopo inicial e podem ser definidos como todo produto que não foi prognosticado, abrangendo metodologias e tecnologias novas, alterações na organização, novos serviços, entre outros. Ressalta-se que os spinoffs são possíveis somente pelas competências assimiladas por meio dos programas de P\&D, sendo essas capacitações e conhecimentos resultados intermediários do processo $^{8}$.

$\mathrm{Na}$ abordagem de resultados diretos e indiretos, as inovações tecnológicas podem ser vistas como um resultado direto da $\mathrm{P} \& \mathrm{D}$, uma vez que proporcionam impactos econômicos passíveis de mensuração por meio da relação impacto/custo do programa, sendo esta uma das avaliações econômicas possíveis dentre outras metodologias consolidadas para esse tipo de análise, tais como os estudos econométricos ${ }^{9}$, que investigam a função dos custos em P\&D na contabilização do crescimento econômico; surveys ${ }^{10}$, que relacionam a P\&D com a economia por meio da aplicação de questionários para um grupo amostral; e os estudos de caso ${ }^{11}$, que avaliam diretamente o processo de inovação e o ciclo de vida de uma tecnologia.

Diferentemente, é mais difícil mensurar os impactos indiretos do programa, embora estes também sejam essenciais para melhor análise de viabilidade e rentabilidade, uma vez que ilustram uma perspectiva mais abrangente do cenário estudado. Hasegawa e Furtado ${ }^{12}$ constataram que os spinoffs são capazes de gerar um impacto econômico 51 vezes maior que o impacto econômico da inovação principal. Esses resultados expressivos atestam que os spinoffs devem ser considerados na metodologia, a fim de identificar o real impacto e a verdadeira importância dos programas de P\&D. Dessa forma, torna-se de grande valia identificar quais os resultados indiretos e quais seus respectivos impactos, que podem ocorrer na esfera econômica e também na esfera social.

Sob essa perspectiva, esse artigo avaliou a efetividade de programas públicos de incentivo às atividades de P\&D, especificamente o Programa de P\&D da ANEEL, propondo uma metodologia capaz de analisar a correlação entre um dos possíveis resultados mensuráveis dos investimentos em $\mathrm{P} \& \mathrm{D}$, o impacto no número de patentes do setor (impacto direto), e os impactos indiretos, sob a perspectiva do consumidor, por meio de relatórios de satisfação dos clientes. Então, desenvolveu-se comparação externa com os Estados Unidos (EUA), que é um dos países referência em inovação.

7 WINARSKI, Tyson. Protecting Electrical Technology through Patents. IEEE Technology and Society Magazine, Wollongong, v. 29, n. 4, p. 20-29, 2010.

8 HASEGAWA, Mirian; FURTADO, André Tosi. Avaliação dos impactos de programas de P\&D. Inovação Uniemp, Campinas, v.2, n.3, p. 40-41, jul./ago. 2006.

9 CAMPOS, André Luis Sica. Identificação de impactos econômicos a partir da pesquisa acadêmica: um estudo de projetos temáticos da FAPESP. 1999. 93 f. Dissertação (Mestrado) - Instituto de Geociências, Universidade Estadual de Campinas, Campinas, 1999.

10 SALTER, Ammon; MARTIN, Ben. The economic benefits of publicly funded basic research: a critical review. Research Policy, v. 30, n. 3, p. 509-532, mar. 2001.

11 SALTER, Ammon; MARTIN, Ben. The economic benefits of publicly funded basic research: a critical review. Research Policy, v. 30, n. 3, p. 509-532, mar. 2001.

12 HASEGAWA, Mirian; FURTADO, André Tosi. Avaliação dos impactos de programas de P\&D. Inovação Uniemp, Campinas, v.2, n.3, p. 40-41, jul./ago. 2006. 


\section{UMA BREVE DEFINIIÇÃo dE INOVAÇÃo}

A inovação pode ser entendida com base em diversos aspectos ou definições. De acordo com Schumpeter ${ }^{13}$, inovar consiste em produzir outras coisas (inovação radical) ou as mesmas coisas de uma forma diferente (inovação incremental) e combinar diferentemente materiais e forças. $\mathrm{Na}$ definição schumpeteriana, a inovação pode ser entendida como o motor do capitalismo. De forma complementar, Alvarez ${ }^{14}$ define inovação como sendo a capacidade de se criar novas formas de gerar e apropriar valor no mercado.

Rosenthal e Moreira ${ }^{15}$, por sua vez, definem a inovação de caráter tecnológico como a aplicação de um novo conjunto de conhecimentos ao processo produtivo, resultando em um novo produto, ou no aprimoramento do produto antigo e/ou no grau de aceitação do produto pelo mercado, conferindo, de maneira geral, um aumento dos lucros e melhor posição da empresa no mercado.

Segundo $\operatorname{Arbix}^{16}$, a inovação pode ser entendida como a primeira comercialização de uma ideia ou projeto, sendo seu locus a empresa. Nesse sentido, observa-se que existe uma diferença entre inovação e invenção, dado que a invenção pode ocorrer em qualquer espaço e não necessariamente possui uma aplicação que será absorvida pelo mercado. Assim, a transformação de uma invenção em uma inovação nem sempre é rápida e exige diferentes tipos de conhecimentos, de capacidade, de habilidade e de recursos. As atividades de P\&D são consideradas a fonte mais importante na geração de novos conhecimentos e o conhecimento pode ser considerado um input e as inovações como um output.

Ainda de acordo com Arbix $^{17}$, o Brasil apresenta políticas de inovação muito orientadas para a pesquisa básica, viés favorável a grandes empresas, enquanto as pequenas e médias ficam marginalizadas e encontram dificuldade em se engajar no processo de inovação, que tem sido a força motora das economias mais desenvolvidas, como os EUA, a Finlândia, a Suécia, o Japão e a Alemanha, que possuem também gastos elevados em P\&D.

Do exposto, constata-se que a inovação tecnológica deve ser resultado de um ambiente que produza ciência de ponta e que influencie, direta e indiretamente, o setor produtivo, especialmente por meio de setores de P\&D implantados nas empresas.

\subsection{Panorama da inovação tecnológica no Brasil}

A expansão, durante as últimas duas décadas, de uma economia globalmente integrada e baseada na inovação está transformando o comércio internacional, as atividades de P\&D e o desenvolvimento da produção industrial, impactando no aumento da competitividade em todo o mundo. Nesse sentido, diferentes países vêm implementando estratégias globais de inovação, a fim de satisfazer os desafios desse novo paradigma, destacando-se a Suiça, o Reino Unido, a Suécia, a Holanda e os EUA, que assumiram as cinco primeiras posições, respectivamente, dentre as regiões mais inovadoras do globo, conforme o relatório da World Intellectual Property Organization (WIPO) - Global Innovation Index 2013.18.

13 SCHUMPETER, Joseph. Capitalismo, socialismo e democracia. Rio de Janeiro: Zahar, 1984.

14 ALVAREZ, Roberto dos R. Inovar é preciso. In: ARBIX, Glauco et al. (Org.) Inovação: estratégia de sete países. Brasília: ABDI, 2010. p. 32-64.

15 ROSENTHAL, David; MOREIRA, Inaldo Lima. Algumas considerações sobre a natureza do processo de capacitação tecnológica: fontes de inovação. Revista de Administração Pública, Rio de Janeiro, v. 26, n. 4, p. 145-160, out./dez. 1992.

16 ARBIX, Glauco. Inovação e desenvolvimento. In: et al. (Org.). Inovação: estratégia de sete países. Brasília: ABDI, 2010, p. 66-91.

17 ARBIX, Glauco. Inovação e desenvolvimento. In: et al. (Org.). Inovação: estratégia de sete países. Brasília: ABDI, 2010, p. 66-91.

18 WORLD INTELLECTUAL PROPERTY ORGANIZATION. Global Innovation Index 2013: The Local Dynamics of Innovation. Genebra, 2013. Disponível em:<http://www.wipo.int/edocs/pubdocs/en/economics/gii/gii_2013.pdf>. Acesso em: 05 ago. 2015 . 
No ranking mundial da $\mathrm{WIPO}^{19}$, o Brasil aparece somente na $64^{\circ}$ colocação dentre os países que mais geram inovação, indicando que ainda há um longo percurso a ser percorrido, existindo muito o que ser aprendido com as experiências mundiais. De fato, Marzano ${ }^{20}$ destaca que a exploração da inovação, no contexto brasileiro, possui história recente, já que a adoção de políticas públicas de inovação, assim como a mensuração dos seus resultados, ocorreu há menos de duas décadas. De acordo com Furtado ${ }^{21}$, historicamente, o desenvolvimento tecnológico mais consistente em empresas brasileiras está associado, primordialmente, a dois fatores: (1) razões de Estado; (2) orientações deliberadas de empresas advindas de acidentes de percurso que permitiram antecipar trajetórias. No mais das vezes, o progresso da tecnologia e a inovação no setor produtivo brasileiro teria ocorrido apenas muito mais tarde ou com uma intensidade muito inferior.

A fim de se observar o panorama da inovação no setor produtivo brasileiro, faz-se válida a análise da Pesquisa de Inovação do IBGE (Pintec) ${ }^{22}$, cuja referência conceitual e metodológica baseia-se no Manual Oslo, que é a principal fonte internacional de diretrizes para coleta e uso de dados sobre atividades inovadoras da indústria, segundo a Organização para a Cooperação e o Desenvolvimento Econômico (OCDE) ${ }^{23}$. Visando a uma avaliação da evolução desses esforços inovativos, observa-se que, entre 2006 e 2008, 38,1\% das indústrias analisadas inovaram em produto e processo, contra 33,4\% no período de 2003 a 2005 . Essa taxa obtida na Pintec 2005 ficou muito próxima do resultado de análise entre o período de 2001 a 2003 $(33,3 \%)$ e acima da apurada para o período 1998-2000 (31,5\%). Assim, percebe-se que, desde 2000, ocorreu aumento da taxa de inovação nas indústrias brasileiras. Contudo, os dados mais recentes indicam que, após esse crescimento, entre 2009-2011 ocorreu declínio para 35,6\%, conforme havia sido previsto pela Agência Brasileira de Desenvolvimento Industrial ${ }^{24}$.

Ainda, os dados chamam atenção para o fato de que, entre 2009-2011, somente 3,7\% e 2,1\% das empresas efetivamente introduziram ao mercado nacional um produto novo ou um processo novo, respectivamente, demonstrando que a maioria das inovações diz respeito ao caráter novo ou substancialmente aprimorado do produto ou processo para a empresa, mas não significando uma novidade para o mercado ${ }^{25}$. Dessa forma, observa-se que há hiato entre as indústrias inovadoras e aquelas que efetivamente implementaram um produto/processo novo ou aprimorado em termos mercadológicos, demonstrando debilidade do setor produtivo brasileiro.

Os resultados da Pintec atestam que modelo de desenvolvimento adotado no Brasil, nas últimas décadas, não criou condições e estímulos para que as indústrias criassem setores de $\mathrm{P} \& \mathrm{D}$ em sua estrutura organizacional, bem como priorizassem a inovação como diferencial competitivo. De fato, somente em 2004, por meio da Lei de Inovação Tecnológica (Lei Federal n. ${ }^{\circ}$ 10.973, de 02 de dezembro de 2004), o Brasil objetivou criar um ambiente propício para aumentar o envolvimento das empresas no desenvolvimento de projetos

19 WORLD INTELLECTUAL PROPERTY ORGANIZATION. Global Innovation Index 2013: The Local Dynamics of Innovation. Genebra, 2013. Disponível em:<http://www.wipo.int/edocs/pubdocs/en/economics/gii/gii_2013.pdf>. Acesso em: 05 ago. 2015.

20 MARZANO, Fábio Mendes. Politicas de inovação no Brasil e nos Estados Unidos: a busca da competitividade, oportunidades para a ação diplomática. Brasília: Fundação Alexandre de Gusmão, 2011.

21 FURTADO, João. Padrões de Inovação na Indústria Brasileira. Disponível em: <http://www.ifhc.org.br/wp-content/uploads/ apresentacoes/1941.pdf>. Acesso em: 2 abr. 2011.

22 INSTITUTO BRASILEIRO DE GEOGRAFIA E ESTATÍSTICA. Pesquisa de inovação tecnológica -2011. Rio de Janeiro, 2013. Disponível em: <http://www.pintec.ibge.gov.br/downloads/pintec2011\%20publicacao\%20completa.pdf>. Acesso em: 10 jan. 2015.

23 ORGANIZAÇÃO PARA COOPERAÇÃO ECONÔMICA E DESENVOLVIMENTO. Manual de Oslo: diretrizes para coleta e interpretação de dados sobre inovação. 2006. Disponível em: <http://www.uesc.br/nucleos/nit/manualoslo.pdf>. Acesso em: 05 ago. 2015.

24 NEGRI, Fernanda de; CAVALCANTE, Luiz Ricardo. Análise dos dados da PINTEC 2011. Nota técnica DISET, n. 15. Brasília: IPEA, 2013. Disponível em: <http://www.ipea.gov.br/agencia/images/stories/PDFs/nota_tecnica/131206_notatecnicadiset15.pdf>. Acesso em: 10 out. 2014.

25 INSTITUTO BRASILEIRO DE GEOGRAFIA E ESTATÍSTICA. Pesquisa de inovação tecnológica - 2011. Rio de Janeiro, 2013. Disponível em: <http://www.pintec.ibge.gov.br/downloads/pintec2011\%20publicacao\%20completa.pdf>. Acesso em: 10 jan. 2015. 
inovadores. Essa lei pretendia elevar o número de parcerias entre empresas, universidades e institutos científicos e tecnológicos, a fim de estimular o processo inovativo para viabilizar o desenvolvimento tecnológico do país ${ }^{26}$. No entanto, muitas questões complexas não foram tratadas nessa normatização, incluindo a criação de mecanismos que permitam uma real conexão com as políticas industrial e tecnológica, e também a ausência de flexibilidade na gestão das instituições de pesquisa ${ }^{27}$.

Observa-se, ainda, no Brasil desafio de transformar o conhecimento científico em produtos ou serviços, gerando contribuições econômicas. Assim, trata-se de um país que produz ciência, mas que não consegue interagir, em um nível adequado, com o setor produtivo. O resultado dessa baixa incorporação de tecnologia de ponta diretamente nos produtos torna-os pouco competitivos, tanto no mercado interno como no externo. Tem-se a necessidade, então, da criação de condições para que o país consiga avançar de forma consistente no campo tecnológico, exigindo, além de mudança institucional e econômica, também uma mudança cultural ${ }^{28}$. É reconhecido que não basta para um país ter realizações em ciência e tecnologia (C\&T), ou mesmo em P\&D; é preciso transformá-los em novos produtos e processos, ou melhorar os existentes.

Logo, entende-se que o Brasil ainda está nos estágios iniciais de assimilação de competências e geração de inovação, devendo melhor enxergar o processo inovativo como um fator-chave para a alavancagem do país, não apenas com relação aos impactos econômicos, mas seus alcances sob outras perspectivas, uma vez que a inovação mobiliza todos os recursos do país, tanto os humanos como os materiais, permeando as diversas dimensões existentes.

Dessa forma, é importante saber como a inovação é planejada; como ela é implantada; como deve ser acompanha; quais as práticas a serem introduzidas para o caso de correções no trajeto; dentre outros questionamentos que possibilitem conhecer soluções similares que funcionaram em outros países e que, eventualmente, podem ser aplicadas no contexto brasileiro, propiciando novos conhecimentos e possíveis novas soluções.

Alvarez $^{6}$ afirma que a construção do futuro do Brasil passa pela promoção da inovação, a qual deve ser considerada um elemento essencial para o crescimento e para o desenvolvimento do país, possuindo especial importância para o desempenho das organizações, que se encontram em um cenário extremamente competitivo no qual a geração de valor deslocou-se da manufatura para bens intangíveis, compostos por informações e conhecimentos adquiridos. Nesse sentido, o autor afirma que a inovação tecnológica tem fundamento econômico e social para o Brasil, de modo que os alcances e os impactos do processo inovativo vão muito além, necessitando de diferentes maneiras capazes de identificar e de mensurar os tipos de inovação e as suas respectivas perturbações.

Marzano ${ }^{10}$ apresenta no seu trabalho as primeiras tentativas de dimensionar a inovação no Brasil, analisando as infraestruturas disponíveis, conforme segue abaixo:

(1) FINEP (Financiadora de Estudos e Projetos): trata-se de uma agência específica para a inovação, sendo uma empresa de natureza pública, criada em 1967 e vinculada ao Ministério da Ciência e Tecnologia (MCT), cujo orçamento multiplicou-se nos últimos anos e possui estrutura singular, comparável a instituições internacionais.

(2) Lei de Inovação e Lei do Bem: a Lei de Inovação (Lei nº 10.973 de 2004) que incentiva parcerias em P\&D entre universidades, institutos de pesquisa e empresas; regula a transferência de tecnologia; e, entre ou-

\footnotetext{
26 BRASIL. Lei n $n^{\circ}$ 10.973, de 24 de dezembro de 2004. Dispõe sobre incentivos à inovação e à pesquisa científica e tecnológica no ambiente produtivo e dá outras providências. Disponível em: <http://www.planalto.gov.br/ccivil_03/_ato2004-2006/2004/lei/ 110.973.htm>. Acesso em: 05 nov. 2014.

27 PEREIRA, José Matias; KRUGLIANSKAS, Isak. Gestão de inovação: a lei de inovação tecnológica como ferramenta de apoio às políticas industrial e tecnológica do Brasil. RAE Eletrônica, São Paulo, v. 4, n. 2, p. 1-15, jul./dec. 2005.

28 CALMANOVICI, Carlos. A inovação, a competitividade e a projeção mundial das empresas brasileiras. Revista da USP, São Paulo, n. 89, p. 190-203, 2011.
} 
tros aspectos, estabelece subsídios e recursos para as atividades regulamentadas por ela. Essa Lei foi criada para tentar alavancar as parcerias e interações entre a pesquisa e o setor produtivo, que se mostram baixas. A Lei do Bem (Lei no 11.196 de 2005) busca criar incentivos fiscais relacionados à inovação.

(3) PAC da Inovação: lançado em 2007, com orçamento de $\mathrm{R} \$ 41,2$ bilhões, denominado também de PACTI (Plano de Ação de Ciência, Tecnologia e Inovação) 2007-2010, atuando nos segmentos de expansão e consolidação do sistema nacional de C\&T, na implementação da inovação tecnológica nas empresas, na $\mathrm{P} \& \mathrm{D}$ em áreas estratégicas e na C\&T e inovação voltada para o desenvolvimento social.

(4) Incentivos à Educação: Plano de Desenvolvimento da Educação (PDE), gerenciado pelo Ministério da Educação, cujo objetivo é elevar a qualidade da educação básica no Brasil, assim como a educação superior e a educação profissionalizante.

(5) INPI e INMETRO: reestruturação do INPI (Instituto Nacional da Propriedade Intelectual), visando reduzir o atraso na concessão de marcas e patentes no país, pois um fator que limita a aplicação das patentes é o tempo entre a "descoberta" e a divulgação, que pode ser de até 3 ou eventualmente 4 anos. Esse "atraso" é relevante em alguns setores, como nos produtos eletrônicos, que ficam obsoletos em poucos anos e as consequências desse "tempo perdido" são muito sérias, pois o acesso público a essas informações é demorado $^{29}$. Na metrologia também está ocorrendo o reaparelhamento do Instituto Nacional de Metrologia, Normalização e Qualidade Industrial (INMETRO), pois se trata de uma atividade em contínua evolução.

(6) EMBRAPII: criada, em 2013, pelo Ministério da Ciência, Tecnologia e Inovação (MCTI) em parceria com a Confederação Nacional da Indústria (CNI), a Associação Brasileira de Pesquisa e Inovação Industrial (Embrapii) tem como objetivo o fomento a projetos de cooperação entre empresas nacionais e instituições de $\mathrm{P} \& \mathrm{D}$, visando à geração de produtos e processos inovadores ${ }^{30}$.

A análise da infraestrutura brasileira permite inferir que se tratam de iniciativas recentes, que vêm ganhando mais espaço nos últimos anos, com aportes maiores. No entanto, o sistema de inovação brasileiro ainda possui lacunas significativas que atrapalham as relações entre os diferentes atores desse processo, como no caso da interação universidade-indústria, que se mostra incipiente, como ocorria nos EUA até a Segunda Guerra Mundial. O progresso de alguns setores, como o eletrônico, é lento, porque há um gap entre a produção científica, o registro das patentes e a disponibilização desse conhecimento. A capacidade do país é elevada, com recursos naturais e intelectuais; contudo, na visão econômica essa transposição tem se mostrado lenta.

\subsection{Panorama da inovação tecnológica nos EUA}

O sistema norte-americano de inovação está estruturado num profundo e amplo sistema de investimentos governamentais obrigatórios e estabelecidos por leis, sendo estes uma maneira de alavancar os projetos de pesquisa em inovação. O Estado é um tomador de riscos, ou seja, tem um papel fundamental na correção das falhas de mercado, proporcionando um ambiente com riscos reduzidos e atraindo investimentos privados, contribuindo para a aplicação da pesquisa básica na indústria e, consequentemente, para o desenvolvimento de produtos e serviços mais competitivos ${ }^{31}$.

É possível observar ainda que o modelo norte-americano está centrado em três eixos fundamentais, sendo (1) a criação, a manutenção e o aperfeiçoamento de mecanismos independentes e de excelência para

29 ROBINSON, Steve. Management, applied research and the free market paradox. Engineering Management Journal, Indiana, v.6, n.6, p. 261-269, 1996.

30 ASSOCIAÇÃO BRASILEIRA DE PESQUISA E INOVAÇÃO INDUSTRIAL. Informações institucionais. Disponível em: <http://embrapii.org.br/categoria/institucional/quem-somos/>. Acesso em: 05 ago. 2015.

31 MATTOS, Paulo; ABDAL, Alexandre. Estados Unidos: mudanças jurídico-institucionais e inovação. In: ARBIX, Glauco et al. (Org.). Inovação: estratégia de sete países. Brasília: ABDI, 2010. p. 92-120. 
avaliar os resultados dos investimentos em inovação; (2) a criação e a manutenção de um ambiente regulatório claro, estável e flexível, dando importância para aspectos como a participação do setor privado através de dispositivos de transferência de tecnologia; (3) e a redução de riscos, atraindo os investimentos privados ${ }^{18}$.

Esses três eixos estão combinados de maneira que o sistema norte-americano funcione e acarrete bons resultados. Assim, tem-se, na avaliação, instrumento que permite a justificativa da realização dos investimentos em inovação, sendo um quesito essencial para a realização de otimizações no processo e para que as políticas públicas se sustentem por um longo prazo; como também a existência de um ambiente regulatório claro, no qual os riscos são reduzidos, que facilita a interação entre os diferentes atores do processo inovativo de modo a respeitar a atribuição de cada um.

A fim de entender o percurso percorrido pelos EUA, faz-se válido pensar na perspectiva histórica vinculado à formação de seu Ecossistema de Inovação, sendo possível fazer uma linha do tempo com início em 1787, quando o Congresso Constitucional conferiu ao parlamento a autoridade para promover o progresso da Ciência e das artes úteis ${ }^{32}$.

Baseado na própria dinâmica da economia norte-americana, segundo Higgs, a mão-invisível fez com que o Estado ocupasse um papel de tomador de riscos, proporcionando um ambiente favorável ao progresso, e, no século XIX, a inovação já era uma questão totalmente alheia ao Estado. Contudo, devido à instabilidade e tensão resultantes dos períodos de guerra, como a com a Segunda Guerra Mundial (1939-1945) e, posteriormente, a Guerra Fria, a sociedade sentiu a necessidade de aproximação com ao governo federal ${ }^{33}$.

Nesse contexto se criou, em 1958, a Agência de Projetos de Pesquisa Avançada (atualmente denominada Agência de Projetos em Pesquisa Avançada em Defesa), como uma divisão de pesquisa do Departamento de Defesa; e a Agência Nacional Aeronáutica e Espacial (NASA), em 1959. Nesse mesmo ano, visando à rápida formação tecnológica de jovens e pesquisadores, o orçamento da Fundação Nacional de Ciências (NSF) foi elevado em quase US $\$ 100$ milhões, atingindo um total de US\$134 milhões. Pouco menos de dez anos depois, em 1968, o orçamento da NSF já chegava próximo a US\$500 milhões, representando um crescimento de quase 15 vezes ao longo dessa década. Esses dados demonstram o papel ativo do Estado norte-americano no investimento em pesquisa, fazendo com que os EUA despontasse no cenário tecnológico de modo a culminar no envio do astronauta norte-americano Neil Armstrong à lua, em $1969^{34}$.

Em 1980, surgia um marco legal para o incentivo dos investimentos em inovação nos EUA, estabelecido por meio da lei Stevenson-Wydler Technology Innovation Act e Bayh-Dole Act, que regulamentavam a transferência tecnológica entre empresas privadas e organizações públicas, permitindo que tecnologias geradas em institutos públicos, ou com financiamento público, pudessem ser transferidas para as organizações privadas. Ainda, essas normatizações representavam o estabelecimento de parcerias entre instituições públicas e o setor produtivo, bem como possibilitavam que universidades se tornassem titulares de tecnologias desenvolvidas por meio de investimentos governamentais ${ }^{35}$.

Outros instrumentos de fomento à inovação continuaram a se desenvolver no contexto norte-americano, a partir da década de 80. Em 1982, a Pensilvânia estabeleceu um dos primeiros programas oficiais de estímulo às parcerias público-privadas, o Benjamin Franklin Partnership Program, que representou a suavização das fronteiras de interação entre as universidades, a indústria e o governo. Ainda em 1982, foi promulgada a Lei de Desenvolvimento e Inovação para Pequenas Empresas, como também a Associação Nacional de Incubadoras de Empresas (NBIA), cujo objetivo era fornecer treinamento e ferramentas de auxílio às novas empresas, em 1985. Em 1986 surgiu a Lei Federal de Transferência Tecnológica, que tornou obrigatória a

32 CERQUEIRA, João da Gama. Tratado da propriedade industrial. São Paulo: RT, 1982.

33 HIGGS, Robert. Crisis and Leviathan: Critical Episodes in the Growth of American Government. New York: Oxford University Press, 1987.

34 TASH, William. Evaluating research centers and institutes for success! Fredericksburg: WT \& Associates, 2006.

35 MARINHO, Vera Maria Costa; SEIDL, Peter Rudolf; LONGO, Waldimir Pirró. O papel governamental como ator essencial para a P\&D de medicamentos: um estudo de casos. Química Nova, São Paulo, v. 31, n. 7, p. 1912-1917, 2008. 
promoção de contratos de cooperação em P\&D e transferência tecnológica entre laboratórios públicos e universidades, bem como entre laboratórios públicos e o setor produtivo. Ainda pode-se destacar que a Lei de Cooperação para a Pesquisa (1984) e a Lei de Comércio e Competitivade (1988) ${ }^{18}$.

Nesse cenário a otimização do sistema de propriedade intelectual dos EUA ocorreu, a fim de colaborar para a efetividade dos resultados advindos das normatizações de incentivo à inovação, por meio da proteção e controle de patentes. Como resultado, houve aumento significativo dos royalties, estimulando os inventores. Ainda, em 2000, as indústrias gastavam mais em P\&D do que o governo e, em 2009, o número de membros da NBIA alcançava cerca de 1.900, sendo desses $25 \%$ estrangeiros provenientes de sessenta países ${ }^{10,36}$.

Tem-se, assim, que os EUA estão buscando, continuamente e de diversas formas, assegurar a sua liderança inovadora por meio da capacidade de geração de conhecimento e competências e sua transformação em valor econômico. Ressalta-se ainda o incentiva e a regulamentação de parcerias entre os diferentes atores do processo inovativo, destacando as ações do governo, que influenciam o ritmo e o rumo das mudanças tecnológicas.

Sob essa perspectiva, ao se comparar a estrutura brasileira com a norte-americana, tem-se que o relacionamento bilateral com os EUA é um possível caminho a ser seguido pelo Brasil, retomando o ponto da aprendizagem por meio de experiências de líderes mundiais no cenário da inovação tecnológica.

\section{Programa de P\&D da ANEel no Brasil}

O setor elétrico brasileiro passou por diversas alterações na sua estrutura, desde a sua origem até os dias atuais. Em linhas gerais, pode-se dividir a evolução do setor em três fases principais, conforme descrito abaixo.

Tudo começou com a introdução da eletricidade no país ainda no Império, com a concessão de D. Pedro II a Thomas A. Edison. Na sequência, entre os anos de 1898 a 1929, ocorreu intenso investimento de capital estrangeiro e nacional, oriundos do setor privado; portanto, nessa primeira fase o setor é considerado privado. Em 1929, com a recessão enfrentada pelo Brasil e a instalação de um governo revolucionário nacionalista, deu-se início à segunda fase (1931-1990), que se referiu à estatização do setor. Na fase estatal, o crescimento do segmento ocorreu por meio de endividamentos externos até a crise dos países em desenvolvimento, na década de 80, que causou uma recessão mundial. Durante esses anos, o governo reajustou as tarifas abaixo da inflação como uma medida de controle, o que gerou mais prejuízos financeiros para o país, sendo proposta reformulação no setor. Nesse contexto, iniciou-se a terceira fase (1992-2009), centrada na privatização e nas reformas. Essa reestruturação ocorreu em conjunto com a reforma do papel do Estado, com o governo Fernando Henrique Cardoso. Essas mudanças precisavam ser reguladas e, nesse contexto, é criada a ANEEL, pela Lei 9.427, de 26 de dezembro de $1996^{37}$.

O final da segunda fase e o início da terceira foi marcado por recessões, o que fez o governo reduzir os recursos públicos destinados a P\&D para empregá-los em outros fins mais imediatos e, simultaneamente, a redução pelas empresas privadas, que naquele momento tinham interesses estratégicos de curto prazo com riscos menores. Visando garantir investimentos mínimos em P\&D, foi promulgada a Lei no 9.991, de 2000, definindo os valores percentuais mínimos de gastos com P\&D, sendo uma obrigatoriedade para todas as empresas autorizadas, permissionárias e concessionárias ${ }^{2}$.

36 FEDERAL LABORATORY CONSORTIUM FOR TECHNOLOGY TRANSFER. The Green Book: Federal Technology Transfer Legislation an Policy. 2013. Disponível em: < http://globals.federallabs.org/pdf/FLC_Legislation_and_Policy.pdf>. Acesso em: 14 maio 2014.

37 CENTRAIS ELÉTRICAS BRASILEIRAS. História do setor de energia elétrica no Brasil. Rio de Janeiro, 2015. Disponível em: <http://www.memoria.eletrobras.com.br>. Acesso em: 14 maio 2014. 
Dessa forma, o programa de P\&D da ANEEL, como é denominado, tem como objetivo gerar inovações com base nos investimentos obrigatórios em atividades de P\&D no setor produtivo, desenvolvendo uma cultura inovadora nas organizações e transferindo para as empresas a responsabilidade de gerenciar os projetos, capacitar os funcionários e estabelecer parcerias com institutos de pesquisa. Entre os anos de 2000 e 2007 , foram arrecadados aproximadamente $\mathrm{R} \$ 1,5$ bilhão, alocados em cerca de 2,4 mil projetos ${ }^{38}$.

É interessante ressaltar que o Brasil vem passando por ciclos no setor elétrico, como foi apresentado. Dessa forma, iniciou-se com a concessão no Império para setores privados, que não logrou êxito, seguido da estatização, que também não obteve sucesso e deixou consequências negativas para o ciclo privado que se seguiu. Esse último já começou fadado ao fracasso, pois, além dos impactos deixados pela fase anterior, teve início sem uma regulamentação adequada (a ANEEL foi criada somente em 1996, anos após o início) e sem ações rápidas e eficazes de estímulo à inovação.

Sob o exposto, observa-se que, para que essa trajetória seja revertida, é fundamental focar em P\&D, buscando inovações e conhecendo e avaliando os resultados, a fim de garantir e justificar a continuidade dessas políticas, pois, como citado anteriormente, a inovação é o fator-chave para o sucesso e o crescimento tanto do setor elétrico como do país.

\section{Metodologia}

Realizou-se um estudo exploratório, integrando pesquisa bibliográfica e coleta e análise de dados secundários, abrangendo a satisfação dos consumidores e o número de patentes do setor elétrico. A investigação iniciou-se com a busca de referências em banco de dados nacionais e internacionais, como IEEEXplore, Elsevier, SCielo e outros, assim como o acervo digital de universidades brasileiras.

De forma sistemática, a metodologia empregada contemplou: (1) estudo e levantamento de dados com base em de relatórios de satisfação do cliente no setor elétrico, sendo utilizado o Índice Aneel de Satisfação do Consumidor (IASC), para o caso brasileiro, e American Customer Satisfaction Index (ACSI), para o caso norte-americano; (2) coleta e análise do número de patentes do segmento elétrico, empregando uma base internacional de dados patentários - World Intellectual Property Organization (WIPO); (3) análise bivariada para duas variáveis quantitativas, por meio da aplicação do Método de Correlação de Pearson (teste paramétrico) e análises inferenciais, a fim de verificar possíveis correlações entre os indicadores, bem como desenvolver previsões para os próximos períodos, utilizando-se o software Microsoft Office Excel 2013, pois este apresenta ferramentas de estatística que são úteis para fundamentar as discussões.

\section{Análise e discussão dos resultados obtidos}

Considerando-se a importância de uma análise crítica que responda ao objetivo proposto no início do trabalho, essa seção está dividida em quatro partes. A primeira delas introduz o IASC, apresentando os seus resultados e fazendo uma comparação com os dados dos EUA, obtidos por meio da ACSI. Posteriormente, é feita uma avaliação do impacto do programa de P\&D da ANEEL no número de patentes do setor e uma comparação externa. Na terceira parte, buscou-se a correlação entre os itens anteriores, finalizando com uma discussão.

38 AGÊNCIA NACIONAL DE ENERGIA ELÉTRICA. Manual do programa de pesquisa e desenvolvimento do setor de energia elétrica. Brasília, 2008. Disponível em: <http://www.aneel.gov.br/cedoc/aren2008316_2.pdf>. Acesso em: 13 jul. 2014. 


\subsection{Análise do Índice ANEEL de Satisfação do Consumidor (IASC)}

A ANEEL promove anualmente o IASC (Índice ANEEL de Satisfação do Consumidor). Os objetivos principais desse índice, conforme apresentado no Relatório Brasil - IASC 2012, são: 1) avaliar, por meio da percepção dos usuários, o grau de satisfação com as concessionárias distribuidoras de energia elétrica; 2) gerar um indicador que mostre a percepção global no setor; 3) permitir uma análise temporal no período 2002-2012. Para que os objetivos propostos sejam alcançados, é conduzida uma pesquisa de campo com base na aplicação de questionários para uma amostra de, aproximadamente, 20.000 clientes, distribuídos no Brasil. O modelo utilizado para análise é composto por cinco variáveis: 1) satisfação global; 2) qualidade percebida (composto pelos itens informações ao cliente, acesso à empresa e confiabilidade nos serviços); 3) valor percebido (dimensão econômica); 4) confiança no fornecedor; 5) fidelidade (intenção de troca). A ANEEL disponibiliza os resultados da pesquisa na forma de relatórios anuais, dos quais foram retirados os dados que serão utilizados nesse estudo para efeitos comparativos (ANEEL, 2012).

A Figura 1 apresenta a evolução global do IASC, no período 2002-2012, sendo traçada uma linha de tendência polinomial de $5^{a}$ ordem e obtendo-se uma extrapolação para os próximos períodos. O coeficiente de determinação $\left(R^{2}\right)$ mediu o grau de proximidade entre os valores observados dentro da amostra e os valores previstos pelo modelo adotado, variando de 0 a 1 , sendo que 1 seria o ajuste perfeito.

Gráfico 1 - Índice global de satisfação do consumidor (2002-2012) - Brasil.

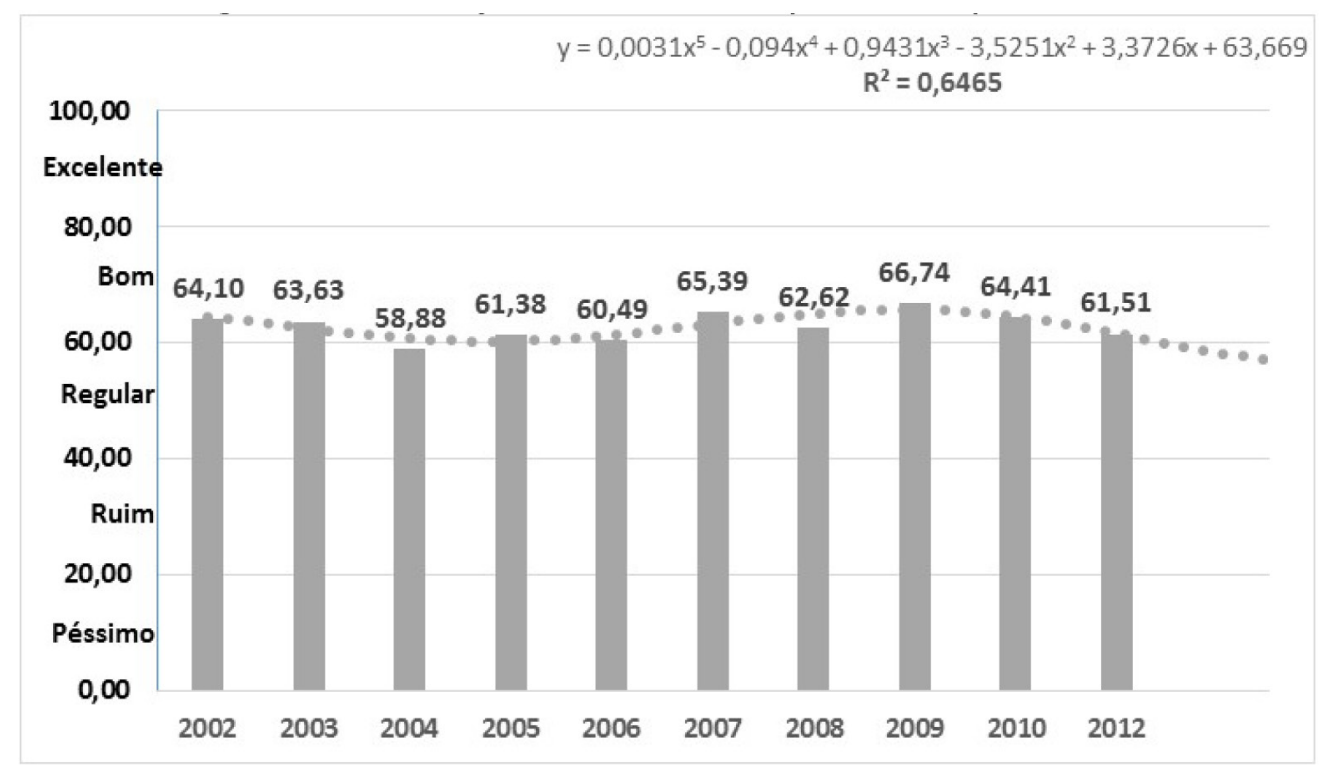

Fonte: Do Autor.

Sob o ponto de vista do consumidor brasileiro, foi possível constatar uma flutuação da satisfação no período avaliado, e especialmente em 2006 e em 2012 o índice encontrava-se na fronteira entre ruim e regular; em 2004 a insatisfação dos clientes foi maior. O índice médio obtido foi de 62,92, permanecendo na faixa considerada entre regular e bom, com tendência para regular e $\mathrm{R}^{2}$ igual a 0,6465 . Não foi constatado um crescimento significativo no índice global, devido à instabilidade nos valores. Ressalta-se que no ano de 2011 não foi publicado o relatório da ANEEL, não sendo possível a obtenção do dado.

Comparativamente, a Figura 2 apresenta a evolução nos EUA, de 2002 a 2012, sendo aferida pela ACSI e disponibilizada em seu sítio eletrônico. 
Gráfico 2 - Índice global de satisfação do consumidor (2002-2012) - EUA.

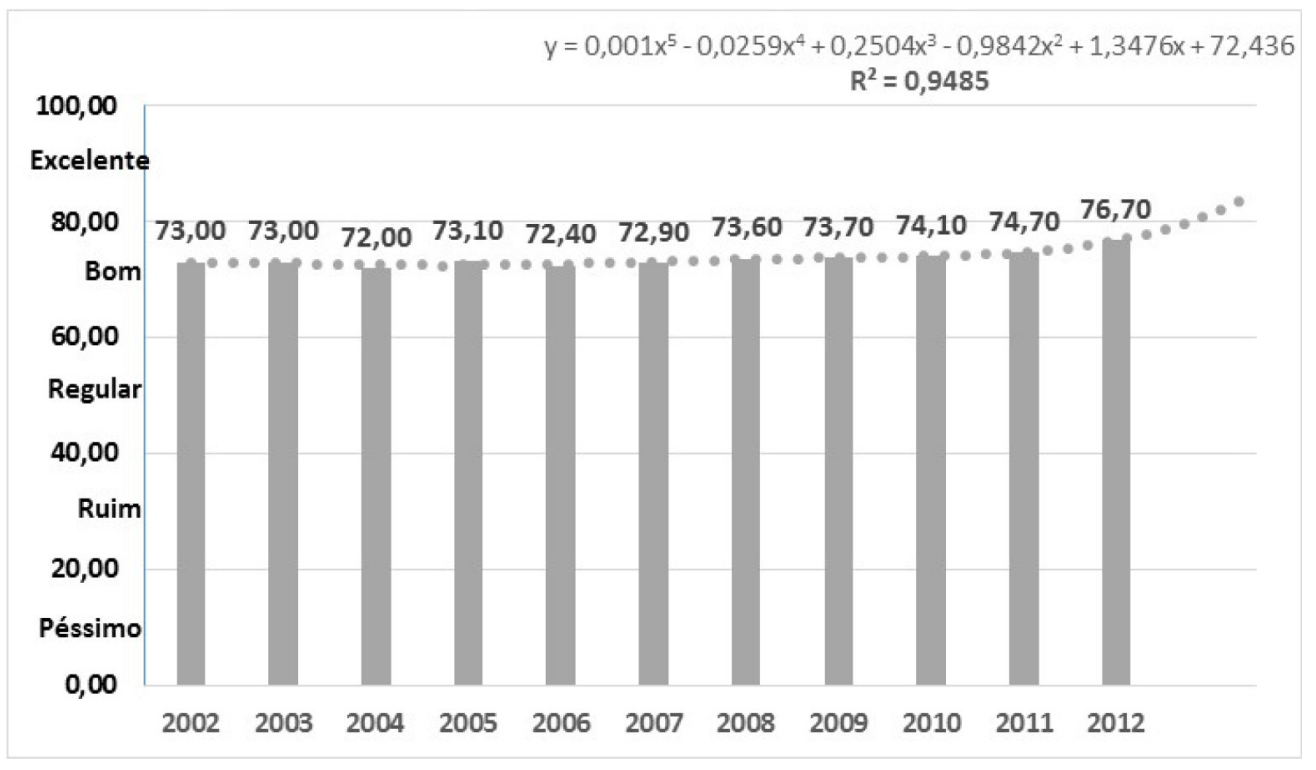

Fonte: Do autor.

No cenário norte-americano, não foi observada flutuação ao longo dos anos, como ocorreu no Brasil, demonstrando sempre uma estabilização da satisfação dos clientes, até 2007 , seguido por uma otimização dos resultados, a partir de 2008. O valor de $\mathrm{R}^{2}$ obtido para o modelo de polinômio de $5^{\mathrm{a}}$ ordem foi de 0,9485 , exibindo maior aderência ao modelo do que o caso brasileiro. Em todo o período avaliado, a amostra permaneceu na faixa entre bom e excelente sob o ponto de vista do consumidor norte-americano, apresentando um índice médio de 73,56. Foi possível observar uma ascensão da linha de tendência e as previsões para os próximos períodos indicaram que um maior aproximação ao nível excelente.

Os valores previstos para ambos os países apresentaram concordância com os recentes relatórios IASC ${ }^{39}$ e $\mathrm{ACSI}^{40}$. Assim, em 2013, realmente houve uma queda no IASC, atingindo 60,41 e ficando na fronteira entre ruim e regular. Em 2014, embora tenha ocorrido uma recuperação na satisfação dos clientes (índice 67,74), há uma manutenção dos valores na faixa regular e bom. No cenário norte-americano, alcançou-se um índice de 77,4, em 2013, e 76,00, em 2014, permanecendo o país na faixa de bom e próximo à fronteira do nível excelente.

\subsection{Análise do número de patentes no setor elétrico}

Os dados utilizados nessa seção foram obtidos no sítio eletrônico da WIPO, também conhecida como Organização Mundial da Propriedade Intelectual (OMPI). Trata-se de uma agência da Organização das Nações Unidas (ONU), sediada em Genebra, responsável pela promoção da proteção da propriedade intelectual no mundo. Sua missão é promover a inovação e a criatividade para o desenvolvimento social, econômico e cultural nos países. Os itens que compõem a propriedade intelectual são a propriedade industrial, que é composta pelas patentes, marcas, desenho industrial e indicações geográficas, os direitos autorais e a proteção sui generis, que abrange os programas de computador, os cultivares e a topografia de circuitos integrados ${ }^{41}$.

39 AGÊNCIA NACIONAL DE ENERGIA ELÉTRICA. Relatório Brasil: IASC 2014. Brasília: ANEEL, 2014. Disponível em: <http://www.aneel.gov.br/arquivos/PDF/RELATORIO_BRASIL_IASC_2014_2.pdf>. Acesso em: 15 jan. 2015.

40 AMERICAN CUSTOMER SATISFACTION INDEX. Customer Satisfaction Benchmarks. Sector: energy utilities. 2015. Disponível em: <http://www.theacsi.org/customer-satisfaction-benchmarks/benchmarks-by-sector>. Acesso em: 22 fev. 2015.

41 WORLD INTELLECTUAL PROPERTY ORGANIZATION. Wipo Overview: 2011 edition. Genebra, 2011. Disponível em: <http://www.wipo.int/export/sites/www/freepublications/en/general/1007/wipo_pub_1007_2011.pdf>. Acesso em: 14 set. 2014. 
Para a análise de correlação que se sucederá na próxima seção, foi escolhida como variável independente o número de patentes, buscando-se verificar, num primeiro momento, se existe algum impacto do programa de P\&D na concessão de patentes do setor. Em seguida, apresenta-se uma comparação com os EUA e a participação do setor elétrico nos pedidos de cada país.

O Manual do Programa de Pesquisa e Desenvolvimento Tecnológico do Setor de Energia Elétrica prevê a propriedade intelectual dos produtos resultantes dos projetos de $\mathrm{P} \& \mathrm{D}$, estimulando a proteção dos direitos de propriedade sobre os produtos gerados, para que a sua comercialização possa contribuir para o desenvolvimento econômico dos agentes participantes desse processo ${ }^{26}$.

Segundo Arbix ${ }^{8}$, o Brasil apresenta atualmente um gasto em P\&D de aproximadamente 1\% do PIB, enquanto nos EUA esse fator era de aproximadamente 2,62\%, em 2006. Winarski ${ }^{4}$ diz que nos EUA a taxa de concessão de patentes no segmente elétrico cresceu significativamente, a partir do ano 2000. Dessa forma, a Figura 3 apresenta o nível de participação do setor elétrico no Brasil, enquanto a Figura 4 ilustra o mesmo cenário para o caso norte-americano.

Gráfico 3 - Pedido de patente por campo tecnológico - Brasil.

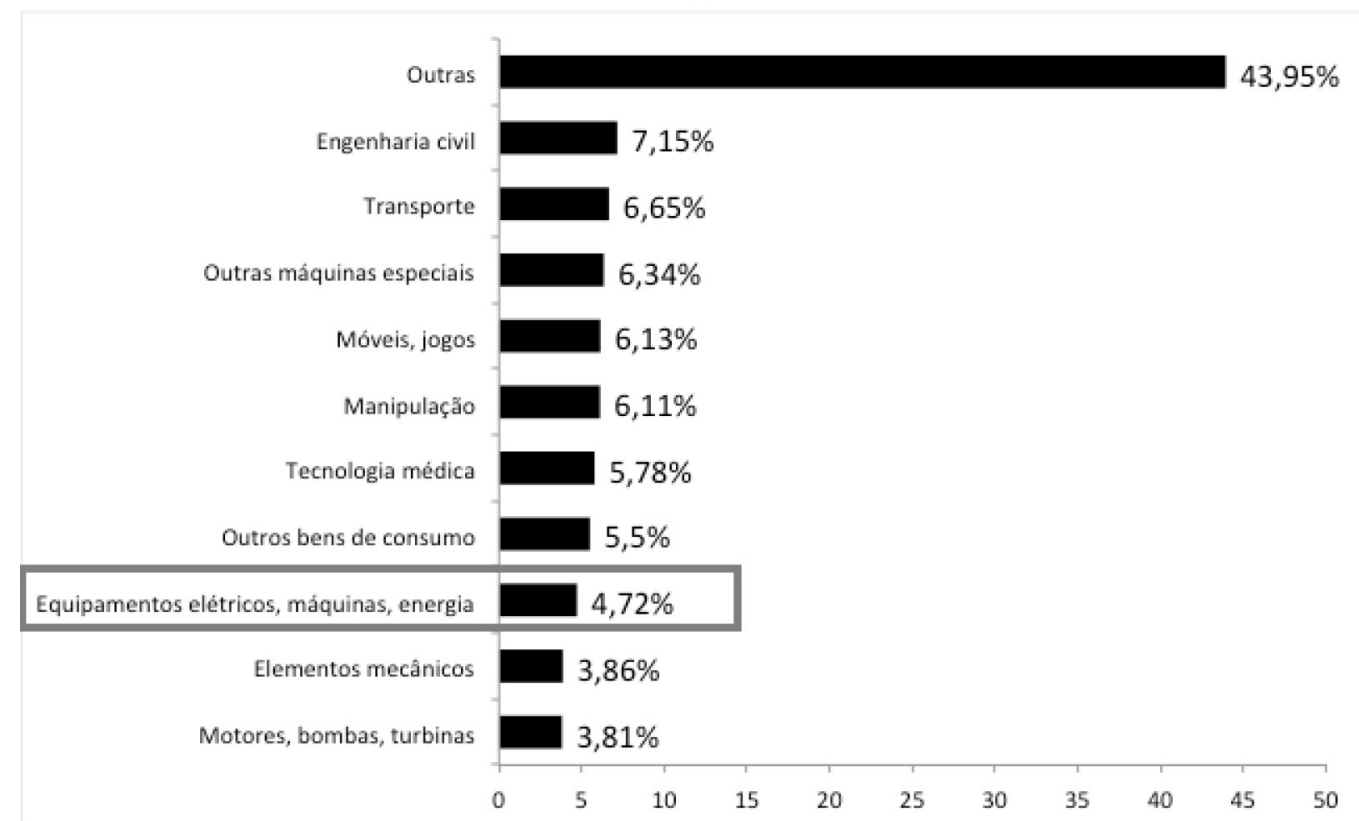

Fonte: adaptado de $\mathrm{WIPO}^{42}$

42 WORLD INTELLECTUAL PROPERTY ORGANIZATION. WIPO statistical country profiles: Brazil. Genebra, 2012. Disponível em: <http://www.wipo.int/ipstats/en/statistics/country_profile/countries/br.html>. Acesso em: 14 set. 2014. 
Gráfico 4 - Pedido de patentes por campo tecnológico - EUA.

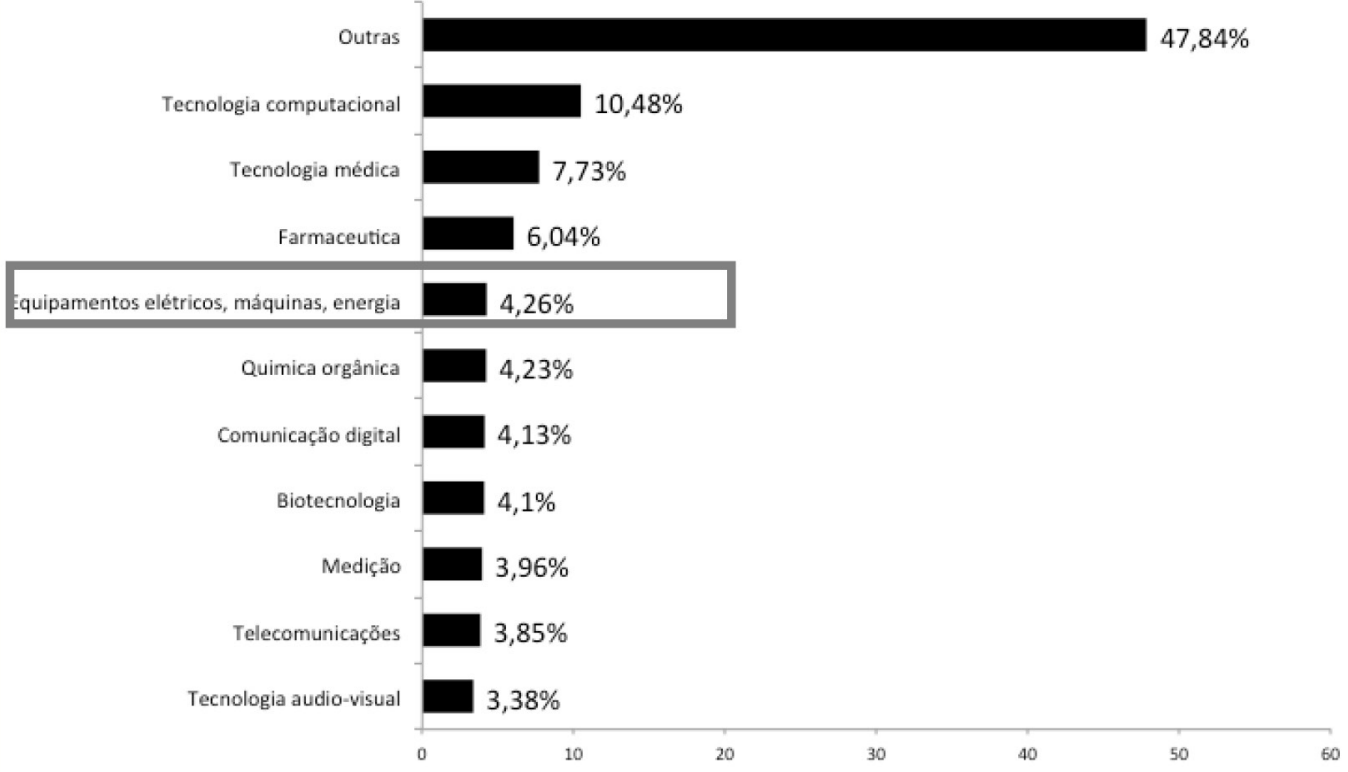

Fonte: adaptado de WIPO ${ }^{43}$

A análise das figuras 3 e 4 demonstra que o Brasil possui um percentual ligeiramente mais elevado de participação do setor elétrico (4,72\%) do que os EUA (4,26\%). Contudo, no contexto brasileiro, esse setor ocupa o $8^{\circ}$ lugar, enquanto nos EUA esse setor desponta em $4^{\circ}$ lugar, apresentando uma importância relativa maior nos EUA do que no Brasil.

As figuras 5 e 6 apresentam o número de patentes publicadas no Brasil e nos EUA, respectivamente, conforme dados da $\mathrm{WIPO}^{44}$. Observa-se que o índice de inovação no Brasil permaneceu instável, com quedas e recuperações constantes, não sendo percebido um crescimento expressivo, de modo que não foi possível evidenciar um impacto efetivo do programa de P\&D da ANEEL, no período analisado. Em valores absolutos, pode-se afirmar que o número de proteções no Brasil é muito baixo, e, em 2011, somente 221 patentes foram obtidas no setor elétrico. Esses dados comprovam o reduzido índice de inovação no setor, bem como a instabilidade do processo inovativo. Contudo, prevê-se aumento no número de proteções brasileiras no segmento elétrico para os próximos anos, tendo como base a linha de tendência polinomial de $5^{\mathrm{a}}$ ordem traçada $\left(R^{2}=0,6758\right)$.

43 WORLD INTELLECTUAL PROPERTY ORGANIZATION. WIPO statistical country profiles: United States of America. Genebra, 2012. Disponível em: <http://www.wipo.int/ipstats/en/statistics/country_profile/countries/us.html>. Acesso em: 14 set. 2014.

44 WORLD INTELLECTUAL PROPERTY ORGANIZATION. WIPO IP statistics data center: indicator: 5 patent publications by technology, report type: total count by applicant's origin, year range: 2002-2011, origin: Brazil and United States, technology: electrical machinery, apparatus, energy. 2012. Disponível em: <http://ipstatsdb.wipo.org/ipstatv2/ipstats/patentsSearch>. Acesso em: 14 set. 2014. 
Gráfico 5 - Evolução no número de patentes do setor elétrico - Brasil.

$$
\begin{gathered}
y=0,1545 x^{5}-4,4814 x^{4}+48,35 x^{3}-237,38 x^{2}+513,78 x-160 \\
R^{2}=0,6758
\end{gathered}
$$

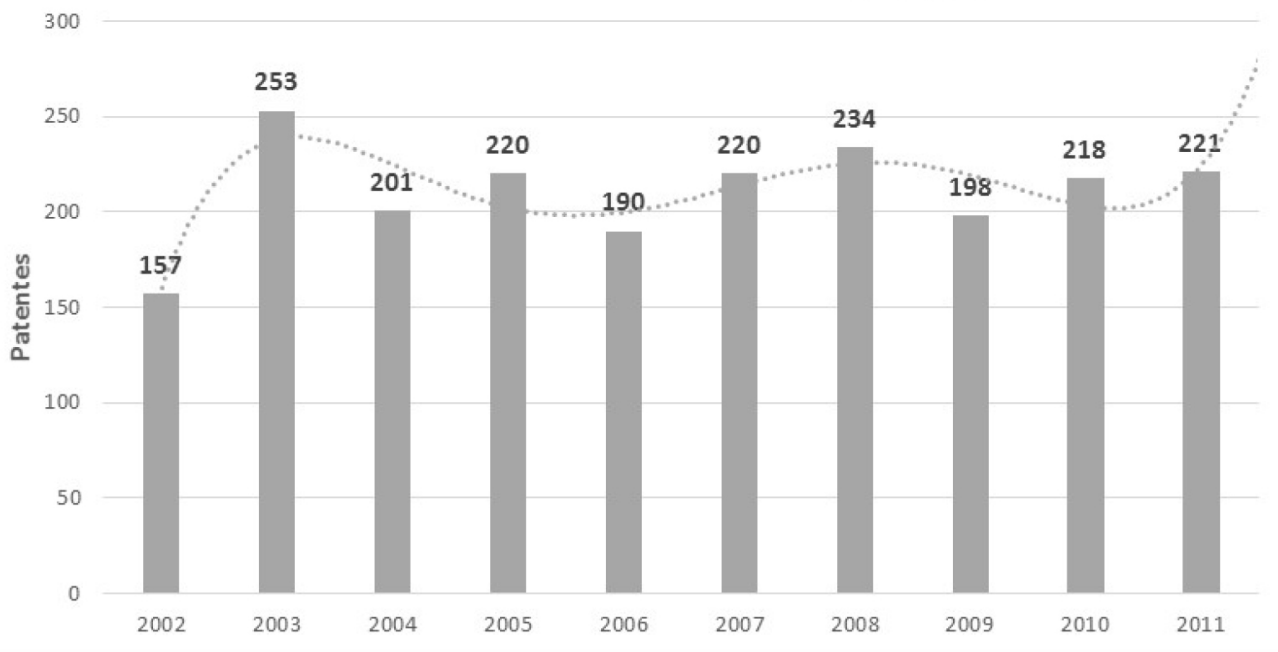

Fonte: Do Autor

De modo distinto, o índice de inovação norte-americano apresentou um discreto crescimento, até 2007, seguido por aumento significativo, em 2008, de modo que o número de proteções saltou de 14.549 (2007) para 15.653 (2008), alcançando 15.782 patentes no setor elétrico, em 2011. Esse comportamento no número de proteções assemelha-se ao observado para o índice de satisfação do cliente, demonstrando que um aumento da inovação no segmento elétrico conferiu maior satisfação do consumidor. Ainda, a linha de tendência polinomial de $5^{a}$ ordem traçada exibiu crescimento, embora modesto, no número de patentes do setor elétrico, para os próximos anos. $\mathrm{O}$ valor de $\mathrm{R}^{2}$ nesse caso foi de 0,9768 , atestando uma alta aderência ao modelo adotado e uma diferença significativa com os dados brasileiros.

Gráfico 6 - Evolução no número de patentes do setor elétrico - EUA.

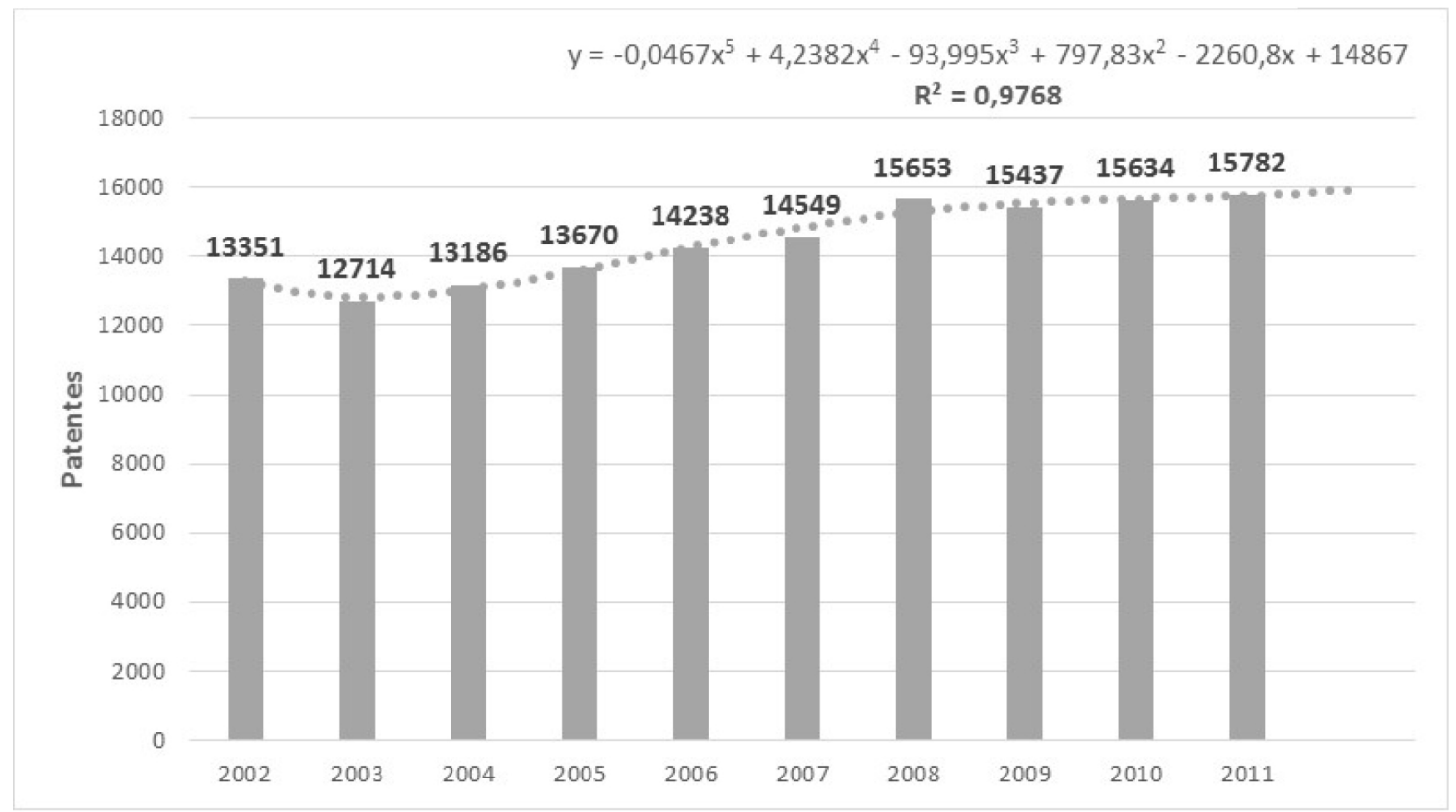

Fonte: Do Autor. 
A diferença entre os números de proteções entre o Brasil e os EUA deve-se, entre outros fatores (como o investimento em P\&D), ao fato de os EUA possuírem uma política de inovação mais consolidada e com forte ligação às ações de $\mathrm{C} \& \mathrm{~T}$, enquanto no Brasil as políticas públicas de inovação, assim como a mensuração de seus resultados, são recentes, sendo inferiores a duas décadas, conforme apresentado no quadro teórico.

\subsection{Análise de correlação entre o número de patentes e a satisfação do consumidor}

A fim de possibilitar análise mais assertiva, o estudo de correlação buscou identificar se existe, e em que grau, associação entre o número de patentes no setor elétrico e o índice de satisfação do consumidor, em cada país. O período avaliado foi 2002-2010, uma vez que a WIPO não apresentou o total patentes referentes à 2012, como também a ANEEL não disponibilizou o índice em 2011, não permitindo, assim, a verificação nesses últimos dois anos.

Nesse artigo, a escolha da análise do coeficiente de correlação de Pearson deve-se ao fato das variáveis de interesse seguirem uma distribuição normal, sendo esta uma condição para a aplicação de testes paramétricos ${ }^{45}$. Ademais, esse método é adotado em cerca de 95\% dos casos para descrever o padrão de relacionamento entre diferentes variáveis ou permitir a realização de inferências pertinentes com base em de dados amostrais ${ }^{46}$.

Dessa forma, aplicou-se o Método de Pearson, sendo $r$ o coeficiente de correlação, que varia entre -1 (correlação perfeita negativa) e 1 (correlação perfeita positiva), que pode ser visto como uma medida da associação linear entre variáveis. O valor 0 (zero) representa que não pode ser constatada correlação, utilizando-se esse modelo. A Tabela 1 mostra as zonas de correlação do modelo e as tabelas 2 e 3 apresentam os dados utilizados na correlação, assim como o resultado para o Brasil e os EUA, respectivamente.

Tabela 1 - Zonas de Correlação do Método de Correlação Pearson

Fonte: Adaptado de Dancey e Reidy (2005)

\begin{tabular}{|c|c|}
\hline $\mathbf{R}^{*}$ & Correlação \\
\hline $0,00-0,30$ & Fraca \\
\hline $0,30-0,70$ & Moderada \\
\hline $0,70-1,00$ & Forte \\
\hline$*$ Os intervalos são equivalentes para valores negativos \\
\hline
\end{tabular}

Tabela 2 - Correlação entre número de patentes e a satisfação dos consumidores (Brasil)

\begin{tabular}{|l|c|c|}
\hline Ano & Patentes (WIPO) & Satisfação (IASC) \\
\hline 2002 & 157 & 64,10 \\
\hline 2003 & 253 & 63,63 \\
\hline 2004 & 201 & 58,88 \\
\hline 2005 & 220 & 61,38 \\
\hline 2006 & 190 & 60,49 \\
\hline 2007 & 220 & 65,39 \\
\hline 2008 & 234 & 62,62 \\
\hline 2009 & 198 & 66,74 \\
\hline 2010 & 218 & 64,41 \\
\hline \multicolumn{3}{|c|}{ r $=\mathbf{0 , 0 4}$} \\
\hline
\end{tabular}

Fonte: Do Autor.

45 ARANGO, Héctor Gustavo. Bioestatística teórica e computacional. 3 ed. Rio de Janeiro: Guanabara Koogan, 2009.

46 CHEN, Peter Y.; POPOVIC, Paula M. Correlation. London: Sage, 2002. 
No cenário brasileiro, não foi constatada uma correlação entre o número de patentes e a satisfação do consumidor $(\mathrm{r}=0,04)$. Esse dado indica que não há uma associação linear entre as variáveis, possivelmente provocado pelas oscilações dos valores já discutidas nos itens anteriores. No entanto, pode haver correlações não lineares, que precisariam ser verificadas em etapas futuras do estudo.

Tabela 3 - Correlação entre número de patentes e a satisfação dos consumidores (EUA)

\begin{tabular}{|c|c|c|}
\hline Ano & Patentes (WIPO) & Satisfação (ACSI) \\
\hline 2002 & 13351 & $\mathbf{7 3 , 0 0}$ \\
\hline 2003 & 12714 & $\mathbf{7 3 , 0 0}$ \\
\hline 2004 & 13186 & $\mathbf{7 2 , 0 0}$ \\
\hline 2005 & 13670 & $\mathbf{7 3 , 1 0}$ \\
\hline 2006 & 14238 & $\mathbf{7 2 , 4 0}$ \\
\hline 2007 & 14549 & $\mathbf{7 2 , 9 0}$ \\
\hline 2008 & 15653 & $\mathbf{7 3 , 6 0}$ \\
\hline 2009 & 15437 & $\mathbf{7 3 , 7 0}$ \\
\hline 2010 & 15634 & $\mathbf{7 4 , 1 0}$ \\
\hline \multicolumn{3}{|c|}{} \\
\hline
\end{tabular}

Fonte: Do Autor.

Nos EUA o resultado mostrou-se diferente, confirmando uma forte correlação positiva entre as variáveis $(\mathrm{r}=0,77)$. Isso significa que existe uma dependência linear entre o número de patentes no setor elétrico e o índice de satisfação do cliente.

\subsection{Discussão}

A partir da contextualização histórica e da análise dos dados, observa-se que o Brasil ainda está dando os primeiros passos no universo da inovação, especialmente no segmento elétrico, iniciando o desenvolvimento das infraestruturas necessárias para esse processo. Uma das maneiras de se evidenciar isso foi por meio da relação entre os investimentos em P\&D, que hoje no Brasil equivalem apenas a 1\% do PIB; e seus respectivos impactos, como a satisfação do cliente e número de patentes no setor. No Brasil o processo de inovação é recente e não está totalmente consolidado, tampouco fortemente inserido no setor produtivo.

Com relação aos impactos diretos, ainda não foi possível perceber um aumento no número de patentes brasileiras no setor elétrico, mesmo com a iniciativa do governo em promover investimentos, por meio do programa de P\&D da ANEEL, cujo objetivo principal é melhorar o desempenho das empresas envolvidas. Corroborando esses resultados, Queiroz ${ }^{47}$ verificou também a não existência de uma relação positiva e estatisticamente significativa entre os gastos com P\&D e o crescimento no lucro de empresas brasileiras analisadas.

Foi possível concluir ainda que, independentemente do país, os retornos econômicos obtidos por meio de investimentos em P\&D geralmente ocorrem em longo prazo e seguem fases, de modo que, inicialmente, deve-se ocorrer o investimento, desenvolvendo novas tecnologias, que, então, serão aplicadas em produtos ou serviços, para, por fim, se obter os retornos econômicos resultantes da comercialização (produto/serviço colocado no mercado).

Ressalta-se ainda que a análise de patentes realizada nesse estudo contemplou um horizonte de tempo de, aproximadamente, dez anos (2002-2011, conforme Figura 5), simultaneamente ao começo do programa

47 QUEIROZ, Odeon. O impacto do crescimento dos gastos em P\&D na taxa de crescimento dos lucros das empresas de acordo com o modelo OJ: um estudo no mercado de capitais brasileiro. In: CONGRESSO ANPCONT, 4., 2010, Natal. Anais... Natal: ANPCONT, 2010. p. 1-16. 
da ANEEL, em 2000. Esse período foi caracterizado pelo investimento e desenvolvimento de projetos tecnológicos, sendo importante determinar os prazos de retorno para cada uma das fases a fim de se avaliar o impacto de cada etapa para o ciclo econômico da inovação.

De maneira mais abrangente, os impactos indiretos da $\mathrm{P} \& \mathrm{D}$ vão além do ciclo econômico da inovação. O impacto indireto adotado como índice nesse trabalho foi a satisfação do cliente. Nesse ponto, até 2012 não foi possível observar um crescimento na satisfação do consumidor brasileiro com base nos dados do IASC. O resultado obtido é uma consequência da satisfação do cliente ser apenas observada após a fase de comercialização, ou seja, quando já houve o investimento, o desenvolvimento e a aplicação da inovação no mercado. Como nesse tempo (2002-2012) não foi possível observar ainda os impactos diretos, também é difícil analisar a correlação com a satisfação do cliente, conforme demonstrado pelo Método de Pearson. Pode-se entender que é cedo para que os clientes percebam os impactos das atividades de P\&D nos serviços cotidianos, considerando-se que essas iniciativas são recentes. No entanto, não basta simplesmente empregar recursos em P\&D; é essencial fiscalizar todo o processo, medir os resultados, fazer ajustes nas políticas, incentivar e orientar o setor produtivo, dentre outras medidas que possibilitem resultados efetivos dos programas de P\&D.

Comparativamente, no que se refere aos EUA, foi possível constatar um crescimento no número de patentes no setor, mesmo sem a identificação, no presente trabalho, de um programa nacional especifico para esse fim no segmento elétrico. Ainda, observou-se uma forte correlação entre o número de proteções no setor e a satisfação dos clientes, podendo ser explicada pelo cenário consolidado existente no país, pois, como essas relações só podem ser evidenciadas no longo prazo, nos EUA existem condições adequadas para que isto ocorra.

\section{ConClusão}

O presente trabalho foi realizado com o objetivo de estudar e avaliar se existe correlação entre um dos possíveis resultados mensuráveis dos investimentos em P\&D regulamentados pela ANEEL, o impacto no número de patentes do setor elétrico, e os impactos indiretos, por meio da satisfação dos clientes expressa na pesquisa IASC. Também, realizou-se uma comparação externa com os EUA.

O estudo demonstrou que, sob a perspectiva do consumidor brasileiro, não foi possível evidenciar uma melhoria no índice IASC, entre 2002 e 2012, permanecendo, em média, na faixa de regular a bom. Foi prevista uma continuação da satisfação dos clientes no nível regular para os próximos períodos. Também não foi constatado o impacto dos investimentos em P\&D no número de patentes do setor elétrico, de modo que o Brasil ainda possui um baixo nível de inovação, especialmente no segmento estudado. Até o presente momento, não foi observada uma relação entre esses gastos em P\&D e a satisfação do consumidor no Brasil.

Comparativamente, nos EUA foi percebido um crescimento no índice de satisfação do cliente, principalmente a partir de 2007. Embora não tenha sido identificado um programa específico para desenvolvimento em $\mathrm{P} \& \mathrm{D}$ no setor elétrico, um mesmo avanço também foi constatado no número de patentes norte-americanas a partir de 2007, indicando uma correspondência entre o índice de inovação e a satisfação do consumidor. De fato, os resultados obtidos por meio da aplicação do Método de Pearson comprovaram uma forte correlação positiva entre essas duas variáveis.

Uma das justificativas para a divergência de resultados entre os países estudados está no fato de a satisfação do cliente somente ser percebida em longo prazo, sendo um resultado do somatório de experiências (positivas ou negativas) vivenciadas pelo consumidor no decorrer do tempo. Nesse sentido, tem-se ainda que o próprio processo de P\&D é longo; as iniciativas do governo brasileiro de incentivo à inovação no setor elétrico são recentes; e, baseado nos indicadores de propriedade intelectual, a geração de patentes e, 
consequentemente, a entrada de novos produtos ou aplicação de novos processos nesse segmento ainda é embrionária, quando comparado aos EUA.

Logo, o presente artigo sugere metodologia capaz de analisar os impactos diretos e indiretos desse tipo de programa, no setor elétrico, e correlacioná-los com os investimentos em P\&D, abrangendo a análise de relatórios de satisfação do consumidor; a busca em banco de dados patentários internacionais; e aplicação de um método de correlação em associação com as inferências pertinentes. Essa sistematização pode ser aplicada para a avaliação da efetividade de outros programas públicos, cabendo, somente, as adequações das variáveis de acordo com o escopo do estudo.

Adotando como exemplo o caso norte-americano, esse estudo sustenta a manutenção de políticas públicas destinadas ao estímulo dos investimentos em P\&D no Brasil no longo prazo, especificamente por meio do Programa de P\&D da ANEEL, a fim de alavancar os índices de inovação no segmento elétrico, bem como aprimorar o padrão de satisfação do consumidor. Contudo, deve-se destacar que a obrigatoriedade de aplicação de recursos em atividades de P\&D por si só não é suficiente, sugerindo fortemente que as políticas públicas desenvolvidas possam prever mecanismos capazes de mensurar os resultados dos programas e de fiscalizar todo o processo no setor produtivo, bem como permitir ajustes e correção de trajeto e facilitar a interação dos diferentes atores envolvidos na inovação.

Vale ressaltar que esse trabalho analisou apenas as correlações lineares entre o número de patentes e a satisfação do cliente. Contudo, pode existir correlações não lineares, que seriam pertinentes para análise em novos trabalhos, assim como buscar um prazo médio de retorno dos investimentos em $\mathrm{P} \& \mathrm{D}$, que pode ser utilizado como parâmetros para avaliar e justificar o crescimento dos recursos destinados a esse fim no país.

\section{REFERÊNCIAS}

AGÊNCIA NACIONAL DE ENERGIA ELÉTRICA. Manual do programa de pesquisa e desenvolvimento do setor de energia elétrica. Brasília, 2008. Disponível em: <http://www.aneel.gov.br/cedoc/aren2008316_2.pdf>. Acesso em: 13 jul. 2014.

AGÊNCIA NACIONAL DE ENERGIA ELÉTRICA. Manual dos programas de pesquisa e desenvolvimento tecnológico do setor elétrico brasileiro. Brasilia, 2001. Disponível em: $<$ http://www.aneel.gov.br/aplicacoes/leitura_arquivo/default.cfm?idaplicacao=56>. Acesso em: 05 ago. 2015.

AGÊNCIA NACIONAL DE ENERGIA ELÉTRICA. Relatório Brasil: IASC 2014. Brasília, 2014. Disponível em: <http://www.aneel.gov.br/arquivos/PDF/RELATORIO_BRASIL_IASC_2014_2.pdf>. Acesso em: 15 jan. 2015.

ALVAREZ, Roberto dos R. Inovar é preciso. In: ARBIX, Glauco et al. (Org.) Inovação: estratégia de sete países. Brasília: ABDI, 2010.

AMERICAN CUSTOMER SATISFACTION INDEX. Customer Satisfaction Benchmarks. Sector: energy utilities. 2015. Disponível em: <http://www.theacsi.org/customer-satisfaction-benchmarks/benchmarks-bysector>. Acesso em: 22 fev. 2015.

ARANGO, Héctor Gustavo. Bioestatística teórica e computacional. 3 ed. Rio de Janeiro: Guanabara Koogan, 2009.

ARBIX, Glauco. Inovação e desenvolvimento. In: et al. (Org.). Inovação: estratégia de sete países. Brasília: ABDI, 2010. p.66-91.

ASSOCIAÇÃO BRASILEIRA DE PESQUISA E INOVAÇÃO INDUSTRIAL. Informações institucionais. Disponível em: <http:/ / embrapii.org.br/categoria/institucional/quem-somos/>. Acesso em: 05 ago. 2015. 
BRASIL. Lei n 9.991, de 24 de julho de 2000. Dispõe sobre realização de investimentos em pesquisa e desenvolvimento e em eficiência energética por parte das empresas concessionárias, permissionárias e autorizadas do setor de energia elétrica, e dá outras providências. Disponível em:<http://www.planalto.gov.br/ ccivil_03/leis/19991.htm>. Acesso em: 18 out. 2014.

BRASIL. Lei n $n^{\circ}$ 10.973, de 24 de dez̧embro de 2004. Dispõe sobre incentivos à inovação e à pesquisa científica e tecnológica no ambiente produtivo e dá outras providências. Disponível em: <http://www.planalto.gov. br/ccivil_03/_ato2004-2006/2004/lei/110.973.htm>. Acesso em: 05 nov. 2014.

CALMANOVICI, Carlos. A inovação, a competitividade e a projeção mundial das empresas brasileiras. Revista da USP, São Paulo, n. 89, p. 190-203, 2011.

CAMPOS, André Luis Sica. Identificação de impactos econômicos a partir da pesquisa acadêmica: um estudo de projetos temáticos da FAPESP. 1999. 93 f. Dissertação (Mestrado) - Instituto de Geociências, Universidade Estadual de Campinas, Campinas, 1999.

CENTRAIS ELÉTRICAS BRASILEIRAS. História do setor de energia elétrica no Brasil. Rio de Janeiro, 2015. Disponível em: <http://www.memoria.eletrobras.com.br>. Acesso em: 14 maio 2014.

CERQUEIRA, João da Gama. Tratado da propriedade industrial. São Paulo: RT, 1982.

CHEN, Peter Y.; POPOVIC, Paula M. Correlation. London: Sage, 2002.

COSTA, Ana Carolina Vital da; ALMEIDA, José Álvaro Jardim de; GOMES, Carla Regina Pása. Investimentos em P\&D no Setor Elétrico Brasileiro: um perfil dos resultados em eco-inovação. Ariús: Revista de Ciências Humanas e Artes, Campina Grande, v. 16, n. 1/2 p. 172-186, jan./dez. 2010.

FEDERAL LABORATORY CONSORTIUM FOR TECHNOLOGY TRANSFER. The Green Book: Federal Technology Transfer Legislation an Policy. 2013. Disponível em: <http://globals.federallabs.org/pdf/ FLC_Legislation_and_Policy.pdf>. Acesso em: 14 maio 2014.

FURTADO, João. Padrões de Inovação na Indústria Brasileira. Disponível em: < http://www.ifhc.org.br/wpcontent/uploads/apresentacoes/1941.pdf>. Acesso em: 2 abr. 2011.

HASEGAWA, Mirian; FURTADO, André Tosi. Avaliação dos impactos de programas de P\&D. Inovação Uniemp, Campinas, v.2, n.3, p. 40-41, jul./ago. 2006.

HIGGS, Robert. Crisis and Leviathan: Critical Episodes in the Growth of American Government. New York: Oxford University Press, 1987.

INSTITUTO BRASILEIRO DE GEOGRAFIA E ESTATÍSTICA. Pesquisa de inovação tecnológica - 2011. Rio de Janeiro, 2013. Disponível em: <http://www.pintec.ibge.gov.br/downloads/pintec2011\%20publicacao\%20completa.pdf>. Acesso em: 10 jan. 2015.

JANSEN, Dorothea; OSTERTAG, Katrin; WALZ, Rainer (Ed.). Sustainability innovations in the electricity sector. New York: Physica-Verlag, 2012.

MARINHO, Vera Maria Costa; SEIDL, Peter Rudolf; LONGO, Waldimir Pirró. O papel governamental como ator essencial para a P\&D de medicamentos: um estudo de casos. Química Nova, São Paulo, v. 31, n. 7, p. 1912-1917, 2008.

MARZANO, Fábio Mendes. Políticas de inovação no Brasil e nos Estados Unidos: a busca da competitividade, oportunidades para a ação diplomática. Brasília: Fundação Alexandre de Gusmão, 2011.

MATTOS, Paulo; ABDAL, Alexandre. Estados Unidos: mudanças jurídico-institucionais e inovação. In: ARBIX, Glauco et al. (Org.). Inovação: estratégia de sete países. Brasília: ABDI, 2010. p. 92-120.

NEGRI, Fernanda de; CAVALCANTE, Luiz Ricardo. Análise dos dados da PINTEC 2011. Nota técnica DISET, n. 15. Brasília: IPEA, 2013. Disponível em: < http://www.ipea.gov.br/agencia/images/stories/PDFs/ 
nota_tecnica/131206_notatecnicadiset15.pdf>. Acesso em: 10 out. 2014.

ORGANIZAÇÃO PARA COOPERAÇÃO ECONÔMICA E DESENVOLVIMENTO. Manual de Oslo: diretrizes para coleta e interpretação de dados sobre inovação. 2006. Disponível em: <http://www.uesc.br/ nucleos/nit/manualoslo.pdf>. Acesso em: 05 ago. 2015.

PEREIRA, José Matias; KRUGLIANSKAS, Isak. Gestão de inovação: a lei de inovação tecnológica como ferramenta de apoio às políticas industrial e tecnológica do Brasil. RAE Eletrônica, São Paulo, v. 4, n. 2, p. 1-15, jul./dec. 2005.

POMPERMAYER, Fabiano Mezadre; NEGRI, Fernanda de; CAVALCANTE, Luiz Ricardo. Inovação tecnológica no setor elétrico brasileiro: uma avaliação do programa de P\&D regulado pela Aneel. Brasília: IPEA, 2011.

QUEIROZ, Odeon. O impacto do crescimento dos gastos em P\&D na taxa de crescimento dos lucros das empresas de acordo com o modelo OJ: um estudo no mercado de capitais brasileiro. In: CONGRESSO ANPCONT, 4., 2010, Natal. Anais... Natal: ANPCONT, 2010. p. 1-16.

ROBINSON, Steve. Management, applied research and the free market paradox. Engineering Management Journal, Indiana, v.6, n.6, p. 261-269, 1996.

ROSENTHAL, David; MOREIRA, Inaldo Lima. Algumas considerações sobre a natureza do processo de capacitação tecnológica: fontes de inovação. Revista de Administração Pública, Rio de Janeiro, v. 26, n. 4, p. 145-160, out./dez. 1992.

SALTER, Ammon; MARTIN, Ben. The economic benefits of publicly funded basic research: a critical review. Research Policy, v. 30, n. 3, p. 509-532, Mar. 2001.

SCHUMPETER, Joseph. Capitalismo, socialismo e democracia. Rio de Janeiro: Zahar, 1984.

SILVA, Evando Mirra Paula e. O significado da pesquisa Mobit. In: ARBIX, Glauco et al. (Org.). Inovação: estratégia de sete países. Brasília: ABDI, 2010. p.24-30.

TASH, William. Evaluating research centers and institutes for success! Fredericksburg: WT \& Associates, 2006.

WINARSKI, Tyson. Protecting Electrical Technology through Patents. IEEE Technology and Society Magazine, Wollongong, v. 29, n. 4, p. 20-29, 2010.

WORLD INTELLECTUAL PROPERTY ORGANIZATION. Global Innovation Index 2013: The Local Dynamics of Innovation. Genebra, 2013. Disponível em:<http://www.wipo.int/edocs/pubdocs/en/economics/gii/gii_2013.pdf>. Acesso em: 05 ago. 2015.

WORLD INTELLECTUAL PROPERTY ORGANIZATION. WIPO IP statistics data center: indicator: 5 patent publications by technology, report type: total count by applicant's origin, year range: 2002-2011, origin: Brazil and United States, technology: electrical machinery, apparatus, energy. 2012. Disponível em: < http:// ipstatsdb.wipo.org/ipstatv2/ipstats/patentsSearch>. Acesso em: 14 set. 2014.

WORLD INTELLECTUAL PROPERTY ORGANIZATION. Wipo Overview: 2011 edition. Genebra, 2011. Disponível em: <http://www.wipo.int/export/sites/www/freepublications/en/general/1007/ wipo_pub_1007_2011.pdf>. Acesso em: 14 set. 2014.

WORLD INTELLECTUAL PROPERTY ORGANIZATION. WIPO statistical country profiles: Brazil. Genebra, 2012. Disponível em: <http://www.wipo.int/ipstats/en/statistics/country_profile/countries/ br.html>. Acesso em: 14 set. 2014.

WORLD INTELLECTUAL PROPERTY ORGANIZATION. WIPO statistical country profiles: United States of America. Genebra, 2012. Disponível em: < http://www.wipo.int/ipstats/en/statistics/country_profile/ countries/us.html>. Acesso em: 14 set. 2014. 
Para publicar na revista Brasileira de Políticas Públicas, acesse o endereço eletrônico www.rbpp.uniceub.br

Observe as normas de publicação, para facilitar e agilizar o trabalho de edição. 